volume. The Index will cover the more substantial articles from 400 British technical periodicals, and the entries in each issue will refer to articles published during the preceding six or seven weeks. The entries will be arranged under alphabetical subject headings, which will be quite precise in indicating the subject scope of each article entered. The main impetus behind the launching of the Index has come from technical college and public librarians who have long felt the need for a reference tool of this kind. A number of industrial libraries has also entered pre-publication subscriptions, including some in the United States. The Index will be in no way competitive with specialized abstracts which many industrial libraries already take. The functions of indexes and abstracts are to a certain extent complementary, and one of the uses of the British Technology Index will be to bridge the time-interval between an article and its abstract when information may otherwise be untraceable. An American counterpart, The Applied Science and Technology Index, has been in existence for some years. Between them the two publications should give technologists and engineers reasonable facilities for keeping abreast of new developments.

\section{Museum of Comparative Zoology, Harvard College}

THE well-known Museum founded by Louis Agassiz in 1859 has just issued the report for 1960 61 , which completes fifteen years of the directorship by Prof. A. S. Romer (Pp. 31, Cambridge, Mass.: Museum of Comparativo Zoology at Harvard College, 1961). He outlines the history of this institution and its early struggles and then introduces his successor, Dr. Ernst Mayr. As usual, various members of the staff travelled widely for conferences, symposia and for study in other institutions. Reports indicate about 100 research projects, completed or under way, and these range from studies on recent birds to fossil trilobites and from the anatomy of whale throats to the chemical trails of insects. Museum display work has also made progress, and in the mammal department new cases have been constructed for the larger dephinids, in the ornithological department new cabinets have been provided for the skin collection, more than 5,500 amphibians and reptiles were catalogued and added to the collections, and sections of the fish serics have been rearranged.

\section{South African Museums}

Is 1961 the South African Council for Scientific and Industrial Research issued a short survey of all the museums in the Republic of South Africa. This has recently been reprinted by the South Africa Museums Association (Pp. 37. Pretoria: South Africa Museums Association, 1961. 5 cents). It was compiled by Mr. Murray Schoonrand, and gives the information in directory format of address, opening hours, staff, general description of the building, administration, together with scope of the collections, publications and finance. It is interesting to note that nearly eighty museums and art galleries are included in the area. This should prove a useful compilation to all professionally interested in museums, and especially to the institutions in South Africa.

\section{Accidental Radiation Injury}

Studies of the effects of ionizing radiations in animals are of limited valuo for human medicine, as the results cannot be reliably extrapolated to man.
It is, therefore, essential to extract the maximum amount of information from the relatively fow observations on persons accidentally exposed to high doses of radiation and those deliberately irradiated under medical supervision for therapeutic purposes. With this aim in view, the International Atomic Energy Agency and the World Health Organization, which have a common interest in radiation medicine, jointly sponsored a scientific meeting bringing together three groups of scientists: those with experience in the treatment of persons accidentally exposed to high doses of radiation; those using large doses of whole-body irradiation for therapeutic purposes; and those working on related problems in experimental animals. An article in a recent issue of the WHO Chronicle discusses some of the work relating to accidental radiation injury; another article reviews the therapeutic applications of wholebody irradiation (15, No. 12; December 1961).

\section{Invasion of a Melanotic Schwannoma by an Adaman- tinoma}

Considerable advances have been made in knowledge of the pigmented integument and the melanomas by the combined efforts of embryologists, anatomists, zoologists and pathologists. It is now generally accepted that there is a specific melanin-forming cell (melanocyte) which originates from the neural crest. the stem-coll being the melanoblast. In mammals, this has been demonstrated in the mouse by Rawles and, until proved otherwise, it may be assumed that a similar histogenesis occurs in man. It has also been shown that the Schwann cells of all peripheral nervefibres are also derived from the neural crest. Tumours and malformations in which both derivatives of the neural crest are concerned are of interest both from an oncological and biological point of view. The association of pigmented and nerve-sheath lesions in neurofibromatosis is well known. In view of the diversity of the lesions and manifestations of this disturbance, it is difficult to be cortain of the solitary nature of the nerve tumours and of the few cases of single pigmented meningiomas and melanotic neurofibromas which have been reported. A recent paper by J. J. Hodson, of the University of Sheffield ( $J$. Path. Bact., 88, No. 2; October 1961), describes a tumour with the histological features of a melanotic schwannoma occurring within the mandible. The tumour was invaded by an adamantinoma: the invasion of one tumour by another is very rare. The biological and embryological importance of this tumour combination lies in the presence of foci of melanocytes in a nerve-sheath tumour in bone, the relevance of melanin-containing Schwann cells, and the morphological evidence of the cytocrinic injection of melanin into the proliferating epithelial cells within the same tumour. Recent electron microscope work on epidermal melanocytes indicates the importance of Masson's conception of cytocrine secretion of melanin from one cell into another.

\section{Dr. E. de Barry Barnett Memorial}

Is honour of the late Dr. E. de Barry Barnett, formerly head of the Department, of Chemistry and then deputy principal of the Sir John Cass College, it is proposed that a Memorial shall be set up in the form of an Exhibition tenable at the College. Contributions should be sent to Dr. S. D Ross, the Appeal Fund Treasurer, at 135 Hendon Way, London, from whom further information is available. 